\title{
EFEKTIVITAS DUKUNGAN SOSIAL DALAM PEMULIHAN TRAUMA PSIKOLOGIS PADA WANITA SETELAH BENCANA ALAM
}

\author{
Anis Sofia Harjanti ${ }^{[1]}$, Febriola Hotmaida Sagala ${ }^{[1]}$, Johanna Elisha ${ }^{[1]}$ \\ ${ }^{[1]}$ Program Studi Kedokteran \\ Fakultas Kedokteran \\ Universitas Sebelas Maret, Surakarta
}

\begin{abstract}
Abstrak
World Health Organization (WHO) menyebutkan Indonesia merupakan salah satu negara yang paling rentan mengalami bencana alam. Badan Nasional Penanggulangan Bencana (BNPB) per 21 Januari 2020 mencatat angka kejadian bencana alam dengan rincian total sebanyak 207 kejadian dan tren kejadian bencana alam diprediksi akan meningkat di tahun 2020. Terjadinya bencana alam memiliki dampak yang cukup besar dalam berbagai aspek kehidupan manusia, salah satunya dampak terhadap kesehatan mental. Wanita adalah salah satu golongan yang memiliki faktor risiko lebih tinggi mengalami gejala gangguan kesehatan mental, maka dari itu untuk mengetahui efektivitas dukungan dalam pemulihan trauma psikologis pada wanita setelah bencana alam dilakukan pencarian data melalui review literatur ini. Ditemukan sebanyak lima hasil yang relevan sebagai sumber utama. Pemberian dukungan yang segera diberikan pada wanita korban bencana alam dapat memberikan efek positif dalam pemulihan trauma psikologis dan menurunkan kemungkinan terjadinya depresi pascabencana alam.
\end{abstract}

Kata kunci: trauma, psikologis, bencana alam, wanita 


\begin{abstract}
World Health Organization (WHO)'s report mentions Indonesia is one of countries that frequently experience natural disasters. Badan Nasional Penanggulangan Bencana (BNPB) as per January 21st 2020 recorded that there are 207 natural disaster incidents and the trend is predicted to increase in 2020. The effects of natural disaster can be significant as it may affect many different aspects of human's lives, one of them is affecting mental health. Women is one of the vulnerable groups who has higher risk factors to experience mental health disorder, therefore, to be able to resolve this issue, we need to understand and have sufficient knowledge about the effectivity of social support used in healing the psychological trauma experienced by women that can be achieved by this literature review. We found five relevant results to be the main journal sources in this literature review. Immediate social support given to women after experiencing natural disaster can affect positively in healing psychological therapy and decrease the risk of depression happening to them.
\end{abstract}

Keyword: trauma, psychological, natural disaster, women 


\section{EFEKTIVITAS DUKUNGAN SOSIAL DALAM PEMULIHAN TRAUMA PSIKOLOGIS PADA WANITA SETELAH BENCANA ALAM}

\section{PENDAHULUAN}

\section{Latar Belakang}

Laporan World Health

Organization (WHO) menunjukkan

bahwa Indonesia merupakan salah satu negara yang paling rentan mengalami bencana alam. ${ }^{1}$ Badan Nasional Penanggulangan Bencana (BNPB) per 21 Januari 2020 mencatat angka kejadian bencana alam di Indonesia dengan rincian putting beliung sebanyak 90 kejadian, banjir 67 kejadian, tanah longsor 45 kejadian, kebakaran hutan dan lahan 3 kejadian, dan gelombang pasang 2 kejadian. BNPB juga menyebutkan tren bencana kemungkinan akan mengalami kenaikan di tahun 2020 jika dibandingkan dengan tahun 2019. ${ }^{2}$

Bencana alam memberi dampak yang cukup besar dalam berbagai aspek kehidupan manusia yang meliputi dampak sosial, ekonomi, kesehatan, dan dalam aspek lainnya. Salah satunya dampak yang masih jarang menjadi perhatian adalah kondisi psikologis masyarakat yang terkena bencana alam. Dampak psikologi ini kerap muncul dan akan menyebabkan efek jangka panjang jika tidak mendapatkan pertolongan yang sesuai. ${ }^{3,4}$

Berdasarkan sebuah studi observasi mengenai prevalensi kesehatan mental tiga bulan setelah terjadi bencana alam di Kota Palu, dampak yang muncul setelah kejadian tersebut adalah timbulnya gangguan mental yang ditandai dengan adanya simtom stres, cemas dan depresi pada individu yang terdampak bencana alam. ${ }^{3}$ Dwidiyanti et al, 2018 dalam penelitiannya mengenai risiko timbulnya gangguan jiwa pada korban gempa di Lombok menjelaskan bahwa terjadinya bencana alam memiliki dampak terhadap perubahan psikologis korban gempa yang ditandai dengan timbulnya gejala psikotik maupun Post-Traumatic Stress Disorder (PTSD). ${ }^{5}$

Parker et al, 2016 juga
menyebutkan lebih lengkap
mengenai dampak bencana alam


terhadap kesehatan mental manusia dewasa yang terdampak meliputi PTSD, depresi, gangguan kecemasan, gangguan penyesuaian, dan tekanan psikologis dengan faktor risiko yang meningkat pada dewasa tua dibanding dewasa muda. ${ }^{6}$

Pendekatan penyelesaian masalah kesehatan mental yang timbul setelah bencana alam sebenarnya telah banyak diteliti, sebuah laporan dari Pemerintah Inggris menyebutkan adanya korelasi positif antara kesiapan menghadapi bencana dengan kesehatan mental sehingga menimbulkan narasi bahwa gangguan mental akibat bencana alam dapat dicegah. Disebutkan juga bahwa gangguan kesehatan mental yang terjadi setelah bencana alam disebabkan salah satunya karena kurangnya kesiapan menghadapi bencana. ${ }^{7}$ Namun, dalam praktiknya upaya edukasi mengenai kesiapan menghadapi bencana masih sulit direalisasikan, Ismail et al, 2016 dalam survei penelitiannya menunjukkan bahwa dari 827 sampel masyarakat Aceh yang dipilih secara acak, 57,6\% memiliki pengetahuan mengenai bencana dengan nilai baik dan $26,0 \%$ memiliki pengetahuan mengenai kesiapan menghadapi bencana dengan nilai baik. Kedua nilai tersebut masih di bawah indikator keberhasilan yang dibuat Pemerintah Aceh sebesar 70,0\%. ${ }^{8}$ Sehingga, kecenderungan untuk timbulnya masalah kesehatan mental pasca bencana alam masih tinggi.

Selanjutnya, peran pemulihan masalah kesehatan mental akibat bencana alam pun diperlukan dan menjadi kebutuhan yang penting karena kesehatan mental akan berdampak terhadap kualitas hidup penderitanya. ${ }^{9}$ Terdapat beberapa metode pendampingan yang dilakukan pada orang-orang dengan riwayat situasi traumatik seperti bencana alam, salah satunya melalui pendampingan dukungan sosial yang berperan sebagai faktor protektif terhadap dampak psikologis yang negatif setelah terjadinya bencana alam. $^{10}$ Penerapan metode pendampingan ini dinilai dapat mencegah dan menurunkan terjadinya dampak psikologis yang berat pada korban bencana alam. 


\section{Rumusan Masalah}

Berdasarkan latar belakang yang telah diuraikan, rumusan masalah dalam tinjauan pustaka ini adalah: apakah kegiatan dukungan sosial efektif terhadap pemulihan trauma psikologis pada wanita setelah bencana alam?

\section{Tujuan}

Tujuan dari penelitian ini adalah untuk mengetahui efektivitas dukungan sosial dalam pemulihan trauma psikologis pada wanita setelah bencana alam.

\section{Manfaat}

Penelitian ini diharapkan dapat memberikan manfaat dalam perkembangan ilmu di bidang pemulihan psikologis masyarakat yang terdampak bencana alam dan juga meningkatkan kesadaran masyarakat tentang pentingnya dukungan sosial terhadap pemulihan trauma psikologis pada masyarakat yang terdampak bencana alam terutama pada wanita, sehingga masyarakat lebih siap ketika menghadapi dampak psikologis yang ditimbulkan oleh bencana alam.

\section{Metode}

Peneliti menggunakan mesin pencari yaitu Pubmed dan Google Scholar sebagai sumber dari penulisan review. Proses pencarian artikel dilakukan pada 17 - 5 Agustus 2020. Kriteria artikel yang digunakan adalah artikel yang diterbitkan dalam lima tahun terakhir, yaitu tahun 2015 hingga 2020. Kata kunci yang digunakan dalam proses pencarian artikel meliputi social support, depression, disaster, dan women yang dikombinasikan menggunakan logika Boolean “AND" Jumlah artikel yang didapatkan awalnya sebanyak 8.545 hasil, namun artikel yang relevan dan diputuskan menjadi artikel rujukan utama penelitian ini berjumlah 5 artikel setelah melalui penapisan berdasarkan judul, kriteria inklusi, dan eksklusi yang sudah ditetapkan. Artikel yang dijadikan sumber adalah artikel dalam Bahasa Indonesia dan Bahasa Inggris.

\section{HASIL DAN PEMBAHASAN}

Wanita dan Trauma Psikologis setelah Bencana Alam

World Health Organization (WHO) menyebutkan bahwa orang yang terdampak keadaan yang 
mengancam, seperti perang atau bencana alam akan rentan mengalami masalah psikologis. Dampak psikologi yang sering terjadi akibat bencana alam adalah Post-Traumatic Stress Disorder (PTSD) dan depresi. Terdapat berbagai faktor pula yang terlibat dalam munculnya PTSD, salah satunya adalah jenis kelamin. WHO menyebutkan bahwa depresi lebih sering terjadi pada wanita. ${ }^{11}$

Pernyataan tersebut didukung dari penelitian lain yang menyebutkan bahwa prevalensi PTSD pada sampel dewasa setahun setelah terjadinya gempa di L'Aquila, Italia pada April 2009 didapatkan hasil yang signifikans pada wanita dan orang yang tidak bekerja sebagai faktor risiko mengalami PTSD. ${ }^{12}$ Sesuai dengan penelitian sebelumnya, hasil penelitian Navarro-Mateu et al, 2017 menunjukkan bahwa salah satu faktor risiko timbulnya PTSD dan gangguan mental setelah terdampak bencana alam adalah jenis kelamin wanita. ${ }^{13}$ Penelitian Teramoto et al, 2017 juga menunjukkan bahwa dampak psikologis lebih banyak terjadi pada wanita dibandingkan pria. $^{14}$

Hal ini terjadi karena adanya perbedaan faktor terjadinya PTSD dan depresi di antara pria dan wanita. Salah satu faktor yang diperkirakan menjadi pemicu yang kuat dalam terjadinya PTSD dan depresi pada wanita adalah faktor hormonal. Selain faktor biologis, peran sosial juga menentukan perbedaan risiko terjadinya dampak psikologis pascabencana antara pria dan wanita. $^{15,16}$

Dukungan Sosial dan Trauma Psikologis setelah Bencana Alam

Penanganan terhadap dampak psikologis yang timbul pascabencana alam terdapat berbagai macam, salah satunya yang berperan adalah dukungan sosial bagi wanita. Dukungan sosial diartikan sebagai suatu tindakan yang dilakukan oleh orang di sekitar korban bencana yang dapat menyediakan sumber daya, seperti emosional, informasi, dalam wujud dukungan yang diperlukan korban. $^{17}$

Beberapa jurnal yang kami gunakan sebagai sumber utama 
menunjukkan adanya hubungan antara peran dukungan sosial dengan gangguan psikologis (depresi dan PTSD) pascabencana alam. Dar et al, 2018 dalam penelitiannya terhadap 87 orang korban bencana banjir di India, diantaranya terdapat 48 wanita, menunjukkan hasil bahwa rendahnya dukungan yang didapatkan korban dari keluarga ataupun teman disekitarnya memperberat depresi akibat bencana alam yang dialami korban. Sedangkan, adanya dukungan sosial dapat meringankan tekanan fisik dan psikologis yang dialami dan membuat korban dapat mengatasi tekanan yang dialami lebih baik daripada individu yang tidak mendapatkan dukungan sosial dari orang di sekitarnya. ${ }^{18}$ Didukung oleh penelitian Lowe, 2016 spesifik pada sampel wanita, menunjukkan hasil bahwa wanita korban bencana yang mendapatkan dukungan sosial yang minim akan cenderung mengalami dan merasakan tekanan psikologis yang lebih berat dibandingkan wanita yang mendapatkan dukungan sosial yang optimal. ${ }^{19}$

Penelitian yang dilakukan Ren et al, 2015 juga menunjukkan hasil yang sama dengan penelitian sebelumnya. Penelitian yang dilakukan pada wanita hamil korban gempa bumi di Cina, menunjukkan hasil bahwa adanya peran dukungan sosial yang dirasakan korban memberikan dampak yang positif dalam pemulihan trauma psikologis. Adanya dukungan sosial yang segera diberikan membuat korban mampu memilih dan mengadopsi cara koping atau penyelesaian masalah secara positif dan menurunkan angka depresi pascabencana alam. ${ }^{20}$

\section{KESIMPULAN}

Bencana alam masih sering terjadi di Indonesia dan dapat menimbulkan banyak dampak bagi korbannya, salah satu dampak jangka panjang yang masih jarang menjadi perhatian adalah dampak psikologis. Munculnya dampak psikologis ini melibatkan beberapa faktor, salah satunya adalah jenis kelamin. Wanita memiliki risiko tiga kali lebih besar untuk mengalami depresi atau PTSD pascabencana daripada pria.

Penanganan segera terhadap kelainan psikologis yang dialami korban perlu untuk dilakukan, salah satunya adalah dukungan sosial. 
Dukungan sosial yang segera diberikan pada wanita korban bencana alam dapat memberikan efek positif dalam pemulihan trauma psikologis pascabencana dan menurunkan kemungkinan terjadinya depresi.

\section{SARAN}

Dukungan sosial yang segera dilakukan pada korban pascabencana dari orang sekitar korban perlu untuk diterapakan di Indonesia untuk mencegah terjadinya dampak psikologis jangka panjang, seperti depresi dan PTSD. Penelitian mengenai efek psikologis pascabencana pada wanita masih cukup terbatas, sedangkan wanita adalah salah satu golongan dengan faktor risiko yang lebih rentan mengalami masalah kesehatan mental. Jika penelitian mengenai efektivitas metode penanganan trauma psikologis pada wanita lebih banyak dilakukan, penanganan yang dilakukan di lapangan dapat dilakukan mengacu pada data tersebut dan diharapkan dapat menyediakan lebih banyak pilihan bagi tenaga kesehatan yang terjun di masyarakat pada keadaan bencana.

\section{Daftar Pustaka}

1. World Health Organization. Emergency Response Preparedness in Indonesia A Consultation Report prepared exclusively for the Indonesia Humanitarian Country Team [Internet]. 2016 [cited $2020 \mathrm{Jul}$ 20]. Available from: https://www.who.int/docs/default source/searo/indonesia/nonwhopublications/2016emergency-responsepreparedness-report-inindonesiaeng.pdf?sfvrsn=1905f2b4_2

2. Badan Nasional Penanggulangan Bencana. BNPB Editorial. UPDATE: Rekapitulasi Data Bencana di Indonesia per 21 Januari 2020 [Internet]. 2020 [cited 2020 Jul 27]. Available from:

https://bnpb.go.id/berita/updatere kapitulasi-data-bencanadiindonesia-per-21-januari-2020

3. Rasido I, Patodo M. Post disaster: Earthquake, tsunami, liquefaction mental health prevalence of Tadulako University students. Enferm Clin [Internet]. 2020 Jun;30 Suppl 
4:214-218. Available from: https://doi.org/10.1016/j.enfcli.20 19.10.071

4. Wynn ST. Natural Disasters: Planning for Psychological First Aid. J Christ Nurs. 2017;34(1):24-8.

5. Dwidiyanti M, Hadi I, Wiguna RI, Ningsih HEW. Gambaran Risiko Gangguan Jiwa pada Korban Bencana Alam Gempa di Lombok Nusa Tenggara Barat. Holist Nurs Heal Sci. 2018;1(2):82.

6. Parker G, Lie D, Siskind DJ, Martin-Khan M, Raphael B, Crompton D, et al. Mental health implications for older adults after natural disasters - A systematic review and meta-analysis. Int Psychogeriatrics. 2016;28(1):1120.

7. Grant C. Disaster preparedness to reduce anxiety and post-disaster stress. In: K4D Helpdesk Report [Internet]. Bringhton, UK: Institute of Development Studies; 2018. Available from: https://assets.publishing.service.g ov.uk/media/5c6bd4bae5274a72b ac384e9/501_Disaster_Preparedn
ess_for_Reduce_Anxiety_and_

Post-Disaster_Stress.pdf

8. Ismail N, Suwannapong N, Howteerakul N, Tipayamongkholgul M, Apinuntavech S. Assessing disaster preparedness and mental health of community members in Aceh, Indonesia: A communitybased, descriptive household survey of a national program. Rural Remote Health. $2016 ; 16(4)$

9. Roudini J, Khankeh HR, Witruk E. Disaster mental health preparedness in the community: A systematic review study. Heal Psychol Open. 2017;4(1).

10. Adam P. McGuire, Gauthier JM, Anderson LM, Hollingsworth DW, Tracy M, Galea S, et al. Social Support Moderates Effects of Natural Disaster Exposure on Depression and Posttraumatic Stress Disorder Symptoms: Effects for Displaced and Nondisplaced Residents. Int Soc Trauma Stress Stud. 2018;31(3):223-33.

11. World Health Organization. Mental Health in Emergencies [Internet]. 2019. Available from: 
https://www.who.int/newsroom/f act-sheets/detail/mentalhealth-inemergencies

12. Cofini V, Carbonelli A, Cecilia MR, Binkin N, di Orio F. Post traumatic stress disorder and coping in a sample of adult survivors of the Italian earthquake. Psychiatry Res [Internet]. 2015 Sep;229(12):353-358. Available from:https://doi.org/10.1016/j.ps ychres.2015.06.041

13. Navarro-Mateu F, Salmerón D, Vilagut G, José Tormo MA, Ruíz7 Merino G, Escámez T, et al. Post-Traumatic Stress Disorder and other mental disorders in the general population after Lorca's earthquakes, 2011 (Murcia, Spain): A cross-sectional study. PLoS One. 2017;12(7):1-16.

14. Teramoto C, Matsunaga A, Nagata S. Cross-sectional study of social support and psychological distress among displaced earthquake survivors in Japan. Japan J Nurs Sci. 2015;12(4):320-9.

15. Olff M. Sex and Gender Differences in Post-traumatic
Stress Disorder: an Update. Eur J Psychotraumatol. 2017;8.

16. Ishiguro A, Inoue M, Fisher J, Inoue $\mathrm{M}$, Matsumoto $\mathrm{S}$, Yamaoka K. Gender-Based Risk and Protective Factors for Psychological Distress in the Midterm Recovery Period Following the Great East Japan Earthquake. Disaster Med Public Health Prep. 2019;13(3):487-96.

17. Schwab-Reese LM, Schafer EJ, Ashida S. Associations of Social Support and Stress with Postpartum Maternal Mental Health Symptoms: Main Effects, Moderation, and Mediation. Women Heal. 2017;57(6):72340.

18. Dar KA, Iqbal N, Prakash A, Paul MA. PTSD and depression in adult survivors of flood fury in Kashmir: The payoffs of social support. Psychiatry Res [Internet]. 2018;261:449-55. Available from: https://doi.org/10.1016/j.psychres .2018 .01 .023

19. Lowe SR. Trajectories of Perceived Social Support Among Low- Income Female Survivors 
of Hurricane Katrina. J Soc Pers

Relat. 2015;32(8):1034-55.

20. Ren J, Jiang X, Yao J, Li X, Liu $\mathrm{X}$, Pang $\mathrm{M}$, et al. Depression, social support, and coping styles among pregnant women after the Lushan earthquake in Ya'an, China. PLoS One. 2015;10(8):119. 